\title{
Are medical students confident in taking a sexual history? An assessment on attitude and skills from an upper middle income country
}

\author{
Farnaza Ariffin ${ }^{1 *}$, Ken Lee Chin ${ }^{2}$, ChirkJenn $\mathrm{Ng}^{3}$, Maizatullifah Miskan', Verna KarMun Lee ${ }^{4}$ \\ and Mohammad Rodi Isa ${ }^{5}$
}

\begin{abstract}
Background: Sexual history training during undergraduate education is essential for preparing future doctors to handle patients' sexual health concerns. The purpose of this study was to assess the attitudes and perceptions of final-year medical students in Malaysia toward sexual history taking and the training they receive from their medical schools.

Methods: The study used a cross-sectional survey of 379 final-year medical students from three medical schools in Malaysia. Students were asked to rate their attitudes and perceptions regarding training on taking sexual histories using a newly developed questionnaire with good internal consistency (Cronbach's alpha $=0.73$ ). Ethics approval was obtained from the relevant medical schools, and the statistical analysis was conducted using SPSS, Version 20.0.

Results: The mean age of participants was $23.58 \pm 0.65$ SD. Participants reported high interest in sexual health and felt it was important for doctors to know how to take a sexual history (95\%). Among the participants, only half felt comfortable in taking sexual histories from patients. The participants identified cultural and religious differences between the doctor and the patient as a potential barrier for discussing sexual health. Participants were aware of their own practice and ability, as well as their limitations, in taking sexual histories. Less than half (46\%) felt that the training they received adequately prepared them to take sexual histories.

Conclusions: This study identified gaps in sexual health training among medical schools in Malaysia. The delivery of sexual health education program should incorporate confidence building and to make students feel comfortable to take sexual histories from patients. The barrier caused by differences in culture or religion between a doctor and a patient may be overcome through cross cultural and cultural competency training. This is important for multi-faith, multi cultural societies such as Malaysia and other similar countries.
\end{abstract}

Keywords: Sexual history, Medical students, Undergraduate, Attitude, Perception, Skills, Training

\section{Background}

Sexual and reproductive health (SRH) is an important aspect of wellbeing. In 2002, the World Health Organization (WHO) defined sexual health as "a state of complete physical, mental and social wellbeing and not merely the absence of disease or infirmity in all matters relating to

\footnotetext{
*Correspondence: Farnaza@salam.uitm.edu.my

1 Department of Family Medicine, Faculty of Medicine, Universiti

Teknologi MARA, Sungai Buloh, Malaysia

Full list of author information is available at the end of the article
}

the reproductive system and to its functions and processes" [1]. This definition changed perceptions toward sexual health to be more holistic, incorporating various aspects of a person. In view of this definition, sexual health problems may present to doctors in various situations, such as sexually transmitted infection (STI), reproductive or pregnancy-related problems, HIV or AIDs, sexual violence, or sexual dysfunction.

STI is increasing worldwide. The WHO estimated the global incidence of STIs in 2008 in people aged 14-49 to be 498.9 million, compared with 300 million cases in 
$2006[2,3]$. This is a global situation and includes uppermiddle income countries [4] such as Malaysia. In a Malaysian national study conducted in 1994-1995, nearly $1.0 \%$ of 1,379 teenagers aged $13-19$ years had engaged in sexual intercourse [5], and this prevalence had increased to $5.4 \%$ in 2001 [6] and $12.6 \%$ in 2005 [7]. "Baby dumping" is a national concern and a result of non-marital sexual relationships leading to unwanted pregnancies, which are culturally taboo in Malaysian society. Police statistics reported 517 cases of baby dumping from 2005 to February 2011 [8].

The true extent of STI in Malaysia is unknown. This is because of various factors, such as under-reporting, under-diagnosis, patients refusing to seek treatment, social embarrassment, and other factors [2]. The first case of HIV in Malaysia was reported in 1986, and, up to December 2006, there were 76,386 cases of HIV reported by the Ministry of Health, with 9,155 deaths $[9,10]$. This has a social and economic impact upon the health service of the country.

For these reasons, it is important for doctors to be able to take a sexual history and explore patients' sexual health problems to diagnose, manage, and counsel patients accordingly. It has been widely reported that doctors find it uncomfortable to approach the subject of sex and to probe into patients' sexual practices $[11,12]$. However, it has also been found that patients would like to discuss their sexual health problems with their doctors and prefer that their doctors initiate the subject [13]. Furthermore, patients would like to discuss these issues with doctors who have adequate knowledge and are comfortable addressing the patient's sexual concerns [13]. Doctors who are comfortable in discussing sexual health issues were found to be more likely to uncover sexual health problems in patients $[14,15]$. High awareness and positive attitudes among doctors are the starting point for the good delivery of sexual health care [16].

Undergraduate training has an important role in introducing sexual history taking to future doctors and in building their confidence and comfort level. Medical students often find it uncomfortable to take sexual histories and feel that they are inadequately trained [16]. In many countries, medical students still receive training in sexual history taking skills, assessment, and management that is variable, non-standardized, and inadequate [17]. Even in developed countries, such as in the UK, where the undergraduate training in sexual history taking has improved, it is still taught in specialist centers such as genitourinary clinics, and students find it difficult to raise the subject in general consultation $[18,19]$.

Medical undergraduate training in Malaysia was found to lack a standardized curriculum on sexual health and sexual history taking [20]. The purpose of this study was to assess the attitudes and perceptions of final-year medical students in Malaysia regarding sexual history taking and the training they receive from their medical schools.

\section{Methods}

\section{Study design and population}

A cross-sectional study was conducted at three medical schools in Malaysia: Universiti Teknologi MARA (UiTM), University Malaya (UM), and International Medical University (IMU). The study was conducted from May to November 2012 and used a newly developed questionnaire. Only final-year medical students were selected, because they have completed most of their training within the curriculum.

\section{Sampling method}

All final-year medical undergraduate students were invited to participate in the study. Participation was on a voluntary basis, and confidentiality was assured. The students were briefed on the purpose of the study, and, for those who agreed to participate, written consent was obtained. Consent forms were collected separately, and the participants were then given the questionnaires to complete anonymously. A minimum sample size of 364 participants was calculated using a population survey sample size calculator, with a 95\% confidence level and a $5 \%$ confidence interval. Ethical approval was obtained from the relevant institutional ethics committee of all three universities.

\section{Study tools: the questionnaire}

We used a self-assessed questionnaire to measure the attitudes and perceptions of medical undergraduate students regarding sexual history taking and training. The questionnaire was designed for students to reflect upon and rate their perceptions regarding their own attitudes on sexual history taking as well as the training they received on the subject.

A review of published literature on SRH and sexual history taking was performed to identify domains to be included in the questionnaire. The attitude and skill domains were identified, and items were created to cover these areas. After the item pool was generated, a team of experts was formed to identify item redundancy, clarity, and content validity. The questionnaire was designed in the English language, as the medical curriculum is taught in English, and students were given the opportunity during the pilot study to give feedback and comment on their understanding of the questionnaire.

The finalized questionnaire consisted of (part 1) survey items and (part 2) demographic details. Part 1 was subdivided into three sections: section A comprised 16 questions to assess the students' attitudes toward sexual 
history taking, section B contained eight items measuring the students' perceptions of their own skills and training, and section $\mathrm{C}$ asked the students to rate the sexual history taking training they received from eight different specialties. In all three sections, respondents recorded responses on a five-point Likert scale, ranging from (1) strongly disagree to (5) strongly agree and including (3) neutral. The questionnaire was pilot tested with 38 finalyear medical students prior to the main study. The Cronbach's alpha of the questionnaire was 0.73 , indicating that the questionnaire was reliable.

\section{Statistical analysis}

Data analysis was conducted using SPSS, Version 20.0. The frequency distribution, measures of central tendencies, and measures of distribution were produced. A descriptive analysis was conducted for all sections. For the analysis, the Likert scale responses were grouped into three categories: "strongly agree" and "agree" were grouped as "agree", "strongly disagree" and "disagree" were combined into "disagree", and neutral remained. Using the mean score for each item, the Kruskal-Wallis nonparametric test was used to analyze the significance of variables with more than two response values (e.g., ethnicity), and the Mann-Whitney test was used to analyze the significance of variables with two response values (e.g., gender). The Mann-Whitney test uses z-scores below -1.96 and above 1.96 to reject the null hypothesis. Only significant items are reported in this study. The significant level was set at $\mathrm{p}=0.05$.

\section{Results}

A total of 379 medical undergraduate final-year students participated in the study, with a response rate of $70 \%$ from the three medical schools. The response rate for men is $80 \%$ and the response rate for women is $65 \%$. The demographic details of the participants are shown in Table 1 .

Table 1 presents the demographic details of the participants. The sample comprised twice the number of females compared to male medical students. This increasing number of females within medical schools is reflected in other Malaysian studies [21, 22]. The ethnic distribution of the participants was representative of the Malaysian population, based on the 2009 population census [23].

Table 2 reports the participants' attitudes toward sexual history taking. Participants agreed that they were interested in sexual health (76\%) and realized the importance of doctors being able to take sexual histories (96\%). Half of the participants felt unsure or uncomfortable discussing sexual health issues with patients. This is also reflected in the way that they responded to items gauging
Table 1 Demographic details of the participants

\begin{tabular}{lcc}
\hline Variables & Frequency (\%) & Mean (SD) \\
\hline All subjects, $n$ (\%) & $379(100)$ & 23.6 (0.65) \\
Age & \\
Gender & \\
Male & $144(38.2)$ & \\
Female & $233(61.8)$ & \\
Race $^{\text {a }}$ & $214(56.5)$ \\
Malay & $120(31.7)$ \\
Chinese & $32(8.4)$ \\
Indian & $11(2.9)$ \\
Others & \\
Religious & \\
Religious constituted & $234(61.2)$ \\
Slightly religious & $113(29.8)$ \\
Not religious & $29(7.7)$ \\
Doctor in family & \\
Yes & $98(26.0)$ \\
No & $278(74.0)$ \\
Sexual activity & \\
Active & $63(16.8)$ \\
No active & $313(82.6)$ \\
Marital status & \\
Single & $356(93.9)$ \\
Married & $21(5.5)$ \\
\hline
\end{tabular}

a Numbers not equal to $n=379$ because of missing data.

feelings of discomfort discussing sexual health issues with adolescents, patients of the other sex, and unmarried sexually active patients, as well as discussing sexual orientation. Cultural or religious differences between the doctor and the patient were identified as a potential barrier in discussing sexual health issues openly. Most participants were able to recognize their limitations in this subject and almost all of them respected patient confidentiality.

Table 3 reports participants' perceptions of their skills and of the training that they receive on sexual history taking. Only $16.3 \%$ of participants identified sexual history taking as easy, and they were divided (30\% disagreed and $27.4 \%$ agreed) on whether they perceived themselves as having adequate skills in performing the task.

With regard to the training received, only half felt that their medical school had prepared them for taking sexual histories. Less than half of the participants felt that had enough exposure as students to taking sexual histories from patients or simulated patients. Nearly half of the participants felt that they had not received adequate sexual history training in medical school.

In the analysis of factors associated with mean scores on attitude and skills items, only sex was found to be significant. Other factors, such as ethnicity, religion, 
Table 2 Percentage and frequency of the participants' responses on their attitudes toward sexual history taking

\begin{tabular}{|c|c|c|c|c|}
\hline No & & Disagree, frequency (\%) & Neutral, frequency (\%) & Agree, frequency (\%) \\
\hline 1. & I am interested in learning about sexual health ${ }^{\mathrm{a}}$ & $10(1.0)$ & $80(21.0)$ & $287(76.0)$ \\
\hline 2. & $\begin{array}{l}\text { I think that It is important for doctors to know how to take a sexual } \\
\text { history }\end{array}$ & $4(1.0)$ & $12(3.0)$ & $363(96.0)$ \\
\hline 3. & I feel that a nurse can take better sexual history ${ }^{a}$ & $140(36.7)$ & $190(50.0)$ & $46(12.3)$ \\
\hline 4. & $\begin{array}{l}\text { I think that It is important to be nonjudgmental when taking a } \\
\text { sexual history }{ }^{\mathrm{a}}\end{array}$ & $9(2.0)$ & $14(4.0)$ & $354(94.0)$ \\
\hline 5. & $\begin{array}{l}\text { I feel comfortable in discussing sexual health problems with } \\
\text { patients }^{\mathrm{a}}\end{array}$ & $64(16.0)$ & $127(34.0)$ & $186(49.0)$ \\
\hline 6. & $\begin{array}{l}\text { I feel comfortable discussing sexual health problems with adoles- } \\
\text { cents }^{\mathrm{a}}\end{array}$ & $69(18.0)$ & $122(32.0)$ & $187(50.0)$ \\
\hline 7. & $\begin{array}{l}\text { I feel comfortable discussing sexual health problems with patients } \\
\text { of opposite gender }\end{array}$ & $110(29.0)$ & $124(33.0)$ & $143(37.0)$ \\
\hline 8. & $\begin{array}{l}\text { I feel comfortable discussing sexual health problems with unmar- } \\
\text { ried but sexually active patients }\end{array}$ & $65(17.0)$ & $110(29.0)$ & $204(54.0)$ \\
\hline 9. & $\begin{array}{l}\text { I feel comfortable in asking patients about their sexual orientation } \\
\text { e.g. homosexuals }{ }^{\mathrm{a}}\end{array}$ & $102(27.0)$ & $122(32.0)$ & $153(40.0)$ \\
\hline 10. & $\begin{array}{l}\text { I feel comfortable in asking patients regarding their sexual prac- } \\
\text { tices e.g."Are you sexually active?", "Do you practice vaginal sex?"a }\end{array}$ & $91(24.0)$ & $115(30.0)$ & $172(45.0)$ \\
\hline 11. & $\begin{array}{l}\text { I feel comfortable in taking a sexual history from patients who are } \\
\text { uneasy in discussing sex }{ }^{\mathrm{a}}\end{array}$ & $175(46.0)$ & $129(34.0)$ & $72(19.0)$ \\
\hline 12. & $\begin{array}{l}\text { I feel that cultural differences are a barrier when discussing sexual } \\
\text { health problems with patients }{ }^{\mathrm{a}}\end{array}$ & $76(19.0)$ & $107(28.0)$ & $195(51.0)$ \\
\hline 13. & $\begin{array}{l}\text { I feel that religious differences are a barrier when discussing sexual } \\
\text { health problems with patients }{ }^{\mathrm{a}}\end{array}$ & $82(22.0)$ & $105(28.0)$ & $191(51.0)$ \\
\hline 14. & $\begin{array}{l}\text { I recognize my own limitations in discussing sexual health issues } \\
\text { with patients }\end{array}$ & $19(4.8)$ & $74(20.0)$ & $286(75)$ \\
\hline 15. & $\begin{array}{l}\text { I have thought about how my own attitudes, beliefs and values } \\
\text { may affect my discussion of sexual health issues with patients }{ }^{\mathrm{a}}\end{array}$ & $27(7.3)$ & $93(25.0)$ & $258(69.0)$ \\
\hline 16. & I believe that it is important to maintain patient confidentiality & $6(1.6)$ & $14(4.0)$ & $359(95.0)$ \\
\hline
\end{tabular}

a Numbers not equal to $n=379$ because of missing data.

Table 3 Percentage and frequency of participants' perceptions of their skills and training received on sexual history taking

\begin{tabular}{|c|c|c|c|c|}
\hline No & & Disagree, frequency (\%) & Neutral, frequency (\%) & Agree, frequency (\%) \\
\hline 1. & I find taking sexual history easy ${ }^{a}$ & $140(37.0)$ & $175(46.0)$ & $63(16.3)$ \\
\hline 2. & I have adequate skills to take sexual history ${ }^{a}$ & $112(30.0)$ & $162(43.0)$ & $104(27.4)$ \\
\hline 3. & $\begin{array}{l}\text { I have adequate skills to put a patient at ease when discussing their } \\
\text { sexual health issues }{ }^{\text {a }}\end{array}$ & $110(29.4)$ & $152(40.0)$ & $116(31.1)$ \\
\hline 4. & $\begin{array}{l}\text { The training in my medical school prepares me to take a sexual } \\
\text { history }\end{array}$ & $88(24.0)$ & $121(32.0)$ & $170(46.0)$ \\
\hline 5. & $\begin{array}{l}\text { I have enough exposure as a medical student to take a sexual his- } \\
\text { tory from a real patient }\end{array}$ & $111(29.0)$ & $127(34.0)$ & $141(38.0)$ \\
\hline 6. & $\begin{array}{l}\text { I have enough exposure as a medical student to take a sexual his- } \\
\text { tory from a simulated patient }{ }^{a}\end{array}$ & $115(30.0)$ & $126(33.0)$ & $135(35.0)$ \\
\hline 7. & $\begin{array}{l}\text { I feel that there is not enough training in the medical school on } \\
\text { how to discuss sexual health problems with patients }{ }^{a}\end{array}$ & $83(22.0)$ & $120(32.0)$ & $175(46.0)$ \\
\hline 8. & $\begin{array}{l}\text { I feel that patients would like to discuss their sexual health prob- } \\
\text { lems with a doctor }{ }^{a}\end{array}$ & $56(15.0)$ & $122(32.0)$ & $200(53.0)$ \\
\hline
\end{tabular}

a Numbers not equal to $n=379$ because of missing data.

having doctors in the family, sexual history, and marital status, were non-significant. Comparing findings by sex, males found taking sexual histories easier than did females $(\mathrm{z}=-3.293, \mathrm{p}=0.001)$. Males rated themselves as having adequate skills more frequently than did females $(z=-3.326, p=0.001)$, and, compared with 
females, males were better able to put patients at ease $(\mathrm{z}=-4.284, \mathrm{p}=0.0001)$.

Table 4 reports the participants' perceptions of adequacy of training in sexual history taking received during their specialty postings. From the responses, obstetrics and gynecology attained the highest percentage scores $(84 \%)$, followed by primary care medicine $(77 \%)$ and general medicine (61\%).

\section{Discussion}

This study has shown that medical students are interested and recognize the importance in attaining skills in sexual history taking. This is echoed in other studies conducted among medical students and practitioners $[19,24]$. This is encouraging because it represents a positive attitude toward the subject and other studies have shown that high awareness and positive attitudes among doctors are the starting point for the good delivery of sexual health care [16].

This study has also highlighted students' concerns, such as feeling uncomfortable discussing sexual health with patients and this is shared by medical students in other parts of the world [16, 25]. Consultations involving sexual health with adolescents, patients of the other sex, and unmarried sexually active patients, as well as discussions on sexual orientation are seen as barriers in taking sexual histories. These findings are similar to other studies where feeling of embarrassment, ill-preparedness, and the lack of a nonjudgmental approach may be barriers in sexual history taking [16, 20, 25-27]. It is clear that the training programs in medical schools need to address these issues, teaching students on how to handle uncomfortable situations and how to remain nonjudgmental.

Cultural and religious differences between the doctor and the patient were identified as a barrier in discussing sexual health. This finding is echoed in studies involving healthcare professionals $[28,29]$. This is a significant finding within a multicultural society, where cultural and religious differences are inevitable. The concern is that, because of these barriers, doctors may shy away from taking sexual histories from patients and, thus, be unable to identify patients' health needs. Cultural competency training has been shown to improve knowledge, attitudes, and skills of health professionals, as well as patient satisfaction [30], it is therefore recommended that such training could be incorporated within the sexual health undergraduate training module.

Nearly half of the student population in this study felt unprepared to take a sexual history and that the training they received was inadequate to provide them with the necessary skills. The importance of undergraduate training in taking sexual histories has been recognized in many medical schools around the world, but there are great differences in the extent to which this topic is covered [19, 20, 31]. In Malaysia, sexual history training remains an ad hoc topic covered by various specialties [20] such as obstetrics and gynecology, primary care medicine, and general medical postings. In this study, students regarded these specialties as better than others at preparing them for sexual history taking. This finding raises the question of whether these specialties should take the lead in training medical students on taking sexual histories or whether other specialties should also be encouraged to explore such training within their curriculum to give students a broader understanding of sexual health.

Similar to another study, student's age, previous exposure to sex, marital status, and religiosity are not significantly associated with preparedness to take a sexual history [32]. Student's sex did have a significant effect: men rated themselves as more adequately prepared than did women, possibly because of gender bias in self-rating questionnaires [33].

Various studies and methods have been introduced in other countries to improve undergraduate training in sexual history taking and sexual health. This includes

Table 4 Participants' perceptions of adequacy of training on sexual history taking received during their specialty postings

\begin{tabular}{llccc}
\hline Specialty & Agree frequency (\%) & Neutral frequency (\%) & Disagree frequency (\%) & Mean score \pm SD \\
\hline Obstetrics and gynecology & $217(84)$ & $44(12)$ & $18(4.8)$ & $3.10 \pm 0.81$ \\
Primary care & $291(77)$ & $72(19)$ & $16(3.8)$ & $2.94 \pm 0.79$ \\
General medicine & $232(61)$ & $102(27)$ & $44(12.1)$ & $2.60 \pm 0.86$ \\
Psychiatry & $185(49)$ & $117(31)$ & $73(19)$ & $2.35 \pm 0.98$ \\
Public health & $131(35)$ & $126(33)$ & $119(32)$ & $2.04 \pm 1.02$ \\
General surgery & $95(25)$ & $134(35)$ & $148(39)$ & $1.84 \pm 0.94$ \\
Pediatrics & $47(12)$ & $103(27)$ & $227(60)$ & $1.37 \pm 0.98$ \\
Orthopedics & $37(9.5)$ & $107(28)$ & $1.32 \pm 0.88$ \\
\hline
\end{tabular}


student observation of history taking [34], student delivery of peer-led sex education [35], genitourinary attachments [19], the use of simulated patients, and workshops $[20,36]$. These methods can be adopted as teaching and learning tools within a sexual history training program. The gaps identified from this study can be used to improve the delivery of sexual health training among medical schools in Malaysia which includes building confidence and to make students feel comfortable to take a sexual history from patients. Cross cultural training and cultural competency training can be incorporated within the curriculum to overcome the cultural and religious barriers between a doctor and a patient.

\section{Limitations}

Our study has several limitations. The questionnaire was prepared in English rather than the local Malay language, and this may have affected the students' perceptions of the questions and their responses. It is possible that not all respondents were completely fluent in English; Malay is the national language in Malaysia, whereas English is taught as a second language in schools. The researchers took this into account and conducted a pilot study as well as content validation on the questionnaire. The researchers also agreed that, because English is the language used for teaching and learning in medical schools in the country, students are expected to be able to understand and respond competently. Another possible limitation is that, although the students' responses were self-reported and anonymous, bias may have resulted from students providing answers that they thought would be more socially and professionally acceptable. Students may also have wished to "please" the researchers with positive answers. Self-rating may introduce bias, although studies have found that students have the ability for self-assessment, and their accuracy increases at their later years of training [37].

\section{Conclusions}

This study identified gaps in sexual health training among medical schools in Malaysia for undergraduate students. Lack of confidence in approaching the subject of sexual health, inadequate preparation were some of the gaps identified. The delivery of sexual health education program should incorporate confidence building and to make students feel comfortable to take a sexual history from patients. The barrier caused by differences in culture or religion between a doctor and a patient can be overcome through cross cultural and cultural competency training and this is important for multi-faith, multi cultural societies such as Malaysia and other similar countries.

\section{Authors' contributions}

FA is the principal investigator for this research and is involved in the planning of the study, data collection, data interpretation, presentation and first author for this manuscript. CKL is a co-researcher and involved in the planning of the study, data interpretation and writing of the manuscript. NCJ is a co-researcher and involved in the planning of the study, data collection and writing of the manuscript. MM is a co-researcher and involved in the planning of the study and writing of the manuscript. VLKM is a co-researcher and involved in the planning of the study, data collection and writing of the manuscript. MRI is a co-researcher involved in data interpretation, statistical analysis and writing of the manuscript. All authors read and approved the final manuscript.

\section{Author details \\ ${ }^{1}$ Department of Family Medicine, Faculty of Medicine, Universiti Teknologi MARA, Sungai Buloh, Malaysia. ${ }^{2}$ Department of Pharmacy Practice, Faculty of Pharmacy, Universiti Teknologi MARA, Shah Alam, Malaysia. ${ }^{3}$ Department of Primary Care Medicine, Faculty of Medicine, University of Malaya, Kuala Lumpur, Malaysia. ${ }^{4}$ Department of Family Medicine, Faculty of Medicine, International Medical University, Bukit Jalil, Malaysia. ${ }^{5}$ Department of Com- munity Medicine, Faculty of Medicine, Universiti Teknologi MARA, Shah Alam, Malaysia.}

\section{Acknowledgements}

We would like to acknowledge funding through a Grant from the Excellence Fund, Research Management Institute (RMI), Universiti Teknologi MARA, Grant Number 600-RMI/ST/DANA 5/3/Dst (308/2011).

\section{Compliance with ethical guidelines}

\section{Competing interests}

The authors declare that they have no competing interest.

\section{Ethical approval}

Ethical approval was obtained from the three institutional ethics committees of Universiti Teknologi MARA; University Malaya, and International Medical University.

Received: 4 August 2014 Accepted: 2 June 2015

Published online: 17 June 2015

\section{References}

1. World health organization (2002) Defining sexual health. Report of a technical consultation on sexual health. WHO Press, Geneva

2. (2008) Clinical practice guidelines, the treatment of sexually transmitted illness, 3rd edition. Ministry of health, Malaysia

3. World health organization (2008) Global incidence and prevalence of selected curable sexually transmitted infections. WHO Press, Geneva

4. Commission on Growth and Development (2008) The growth report: strategies for sustained growth and inclusive development. @ World Bank, Washington, DC

5. National Population and Family Development Board (1998) Report of the National Study on Reproductive Health and Sexuality 1994/1995. National Population and Family Development Board, Kuala Lumpur

6. Lee LK, Chen PC, Lee KK, Kaur J (2006) Premarital sexual intercourse among adolescents in Malaysia: a cross-sectional Malaysian school survey. Singap Med J 47(6):476-481

7. Anwar M, Sulaiman SA, Ahmadi K, Khan TM (2010) Awareness of school students on sexually transmitted infections (STIS) and their sexual behavior: a cross-sectional study conducted in Pulau Pinang, Malaysia. BMC Public Health 10:571

8. Abdul Rahim A, Tengku Zainudin TNA, Mohd Shariff AA (2012) Curbing the problems of baby dumping and infanticide: a Malaysian Legal Perspective. Int J Humanit Soc Sci 2(12):173-178

9. (2006) AIDS/STD section, summary of HIV/AIDS cases. Disease Control Division, Ministry of Health, Malaysia 
10. (2008) Clinical practice guidelines. Management of HIV infection in pregnant women. Ministry of Health, Malaysia

11. Skelton JR, Matthews PM (2001) Teaching sexual history taking to health care professionals in primary care. Med Educ 35:603-608

12. Verhoeven $V$, Bovijn $K$, Helder A, Peremans L, Hermann I, Van Royen P et al (2003) Discussing STIs: doctors are from Mars, patients from Venus. Fam Pract 20(1):11-15

13. Wittenberg A, Gerber J (2009) Recommendations for improving sexual health curricula in medical schools: returns from a two arm study collecting data from patients and medical students. J Sex Med 6:362-368

14. Burnap DW, Golder JS (1967) Sexual problems in medical practice. J Med Educ 42:673-682

15. Bachmann GA, Lieblum SR, Grill J (1989) Brief sexual inquiry in gynecologic practice. Obstet Gynecol 73b(3, Pt 1):425-427

16. Branderburg U, Bitzer J (2009) The challenge of talking about sex: the importance of patient-physician interaction. Maturitas 63:124-127

17. Sharon J, Parish MD, Anita H, Clayton MD (2007) CME: sexual medicine education: review and commentary. J Sex Med 4(2):250-268

18. Cowan FM, Adler MW (1994) Survey of undergraduate teaching in genitourinary medicine in Britain. Genitourin Med 70:311-313

19. FitzGerald M, Crowley T, Greenhouse P, Probert C, Horner P (2003) Teaching sexual history taking to medical students and examining it: experience in one medical school and a national survey. Med Educ 37:94-98

20. Ng CJ, McCarthy SA (2002) Teaching medical students how to take a sexual history and discuss sexual health issues. Med J Malays 57(Suppl E):44-51

21. Myint $Y Y$, Tun $Y$ (2008) Gender ratio in undergraduate medical program, Medical Faculty, IIUM. Int Med J Malays 7(1 Suppl):150

22. Zulkifli A, Rogayah J (1997) Career preferences of male and female medical students in Malaysia. Med J Malays 52(1):76-81

23. Department of Statistics Malaysia Census. Changing patterns of utilization and analysis of population census data. In: Proceedings of the 24th population census conference: March 2009; Hong Kong, China. http://www.ancsdaap.org/cencon2009/Papers/Malaysia/Malaysia. paper\%2Bappendix.pdf

24. Khanam M, Perveen S, Mirza S (2011) Reproductive and sexual health issues: knowledge, opinion and attitude of medical graduates from Karachi. J Pak Med Assoc 61(7):648-652
25. Dixon-Woods M, Regan J, Robertson N, Young B, Cordle C, Tobin M (2002) Teaching and learning about human sexuality in undergraduate medical education. Med Educ 36:432-440

26. Ashton MR, Cook RL, Wiesenfeld HC, Krohn MA, Zamborsky T, Scholle SH et al (2002) Primary care physician attitudes regarding sexually transmitted diseases. Sex Transm Dis 29(4):246-251

27. Bartlik BD, Rosenfeld S, Beaton C (2005) Assessment of sexual functioning: sexual history taking for health care practitioners. Epilepsy Behav 7:S15-S21

28. Ho TM, Fernandes M (2006) Patient's sexual health: do we care enough? J Renal Care 32(4):183-186

29. Gott M, Galena E, Hinchliff S, Elford H (2004) "Opening a can of worms": GP and practice nurse barriers to talking about sexual health in primary care. Fam Pract 21(5):528-536

30. Beach MC, Price EG, Gary TL, Robinson KA, Gozu A, Palacio A et al (2005) Cultural competency: a systematic review of health care provider educational interventions. Med Care 43(4):365-373

31. Temple-smith MJ, Mulvey G, Keogh L (1999) Attitudes to taking a sexual history in general practice in Victoria, Australia. Sex Transm Infect 75:41-44. doi:10.1136/sti.75.1.41

32. Vollmer S, Wells K, Blacker KH (1989) The preparedness of freshman medical students for taking sexual histories. Arch Sex Behav 18(2):167-177

33. Petrides KV, Furnham A (2000) Gender differences in measured and selfestimated trait emotional intelligence. Sex Roles 42(5/6):450-461

34. Vollmer S, Wells K, Blacker KH, Ulrey G (1989) Improving the preparation of preclinical students for taking sexual histories. Acad Med 64:474-479

35. Faulder GS, Riley SC, Stone N, Glasier A (2004) Teaching sex education improves medical students' confidence in dealing with sexual health issues. Contraception 70:135-139

36. Haist SA, Griffith $\mathrm{CH}$, Hoellein AR, Talente G, Montgomery T, Wilson JF (2004) Improving students' sexual history inquiry and HIV counseling with an interactive workshop using standardized patients. J Gen Intern Med 19:549-553

37. Blanch-Hartigan D (2011) Medical students' self assessment of performance: results from three meta-analysis. Patient Educ Couns 84:3-9

\section{Submit your next manuscript to BioMed Central and take full advantage of:}

- Convenient online submission

- Thorough peer review

- No space constraints or color figure charges

- Immediate publication on acceptance

- Inclusion in PubMed, CAS, Scopus and Google Scholar

- Research which is freely available for redistribution

Submit your manuscript at

www.biomedcentral.com/submit

C Biomed Central 